\title{
Epidural catheter migration during labour: an hypothesis for inadequate analgesia
}

\begin{abstract}
The purpose of this study was to determine the incidence and factors associated with poor analgesia during epidural block for labour pain. Emphasis was placed on determining the incidence, magnitude and factors associated with epidural catheter migration as well as any relationship between catheter migration and the quality of analgesia. Catheter movement was assessed, prospectively, in 211 consecutive parturients who had an epidural catheter placed for labour analgesia. The magnitude and direction of catheter movement was assessed by measurement of the length of the catheter at the skin at the time of epidural placement, and immediately before removal of the catheter, after delivery. Fifty-four per cent of the catheters migrated during labour and 70 per cent of these migrated out of the epidural space. The quality of analgesia provided by the epidural block was assessed by the caseroom nurse caring for the patient. Seventeen per cent of the patient.s had unsatisfactory analgesia. There was an increase in poor analgesia in those patients whose catheters migrated compared with those in whom the catheters were stable $(P<0.05)$. We conclude that catheter migration during labour results in a greater incidence of inadequate block and unsatisfactory analgesia.
\end{abstract}

Dans cette étude, nous avons analysé prospectivement l'efficacité analgésique de 211 blocs périduraux successifs chez des parturientes et l'avons mis en relation avec le déplacement éventuel du cathéter péridural mesuré en comparant sa position lors de l' insertion à celle précédent son retrait, après l' accouchement. Près de 54 pour cent des cathéters se sont déplacés durant le travail et sept fois sur dix, en sortant de l'espace péridural. $D^{\prime}$ après leur infirmière, 17 pour cent des patientes avaient une

\section{Key words}

ANAESTHESIN: obstetrical;

ANAESTHETIC TECHNIQUES: epidural, lumbar; EQUIPMENT: catheter, epidural.

From the Department of Anaesthesia, Ottawa General Hospital, University of Ottawa, 501 Smyth Road, Ottawa, Ontario, K1H 8L6.

Address correspondence to: Dr. E.T. Crosby. analgésie inadéquate et nous avons identifié la migration du cathéter comme facteur de risque significatif $(P<0,05)$ dans la genèse de ce problème.

Epidural block is a well-established method of providing labour analgesia. However, inadequate block may result in unsatisfactory analgesia in a proportion of parturients.' The purpose of this study was to determine the incidence of inadequate analgesia and to explore some of the factors associated with the poor outcomes. As well, the incidence, magnitude and direction of epidural catheter migration were determined and the association of catheter migration with unsatisfactory analgesia was assessed.

\section{Methods}

The study was carried out as part of a larger quality assurance audit for the hospital's Medical Advisory Committee. The protocol was submitted to the hospital's Medical Ethics Committee for review and it was determined that patient consent was not required. Data were gathered, prospectively, from 225 consecutive parturients, at 34 to 42 weeks gestatational age, having epidural block instituted for analgesia during Stage I labour. All blocks were performed by anaesthesia residents on call to the labour and delivery suite on a $24-\mathrm{hr}$ rota. Maternal height and weight were obtained from antenatal charts or nursing evaluations and confirmed by patient interviews. Body mass index was calculated from the recorded height and weight. The patient position, interspace utilized and the depth of the epidural space from skin were recorded. A 17-gauge Tuohy needle, with an 8-cm shaft marked in $1-\mathrm{cm}$ increments was employed and the skin to epidural space distance was measured as described by Doughty. ${ }^{2}$ Once the epidural space was located, a Portex three-holed catheter was passed into the epidural space. The length of the catheter inserted into the epidural space and the length of the catheter at the skin level at the time of taping were recorded. The depth of the epidural space was subtracted from the length of the catheter measured at the skin level to obtain a value for the length of catheter remaining in the epidural space, at time of taping. The catheters were 
secured in position by coiling the catheter on the skin and covering the coil by a transparent, occlusive dressing. The remainder of the catheter was secured to the skin with three-inch micropore tape, running up the back to either the right or left shoulder. Catheters remained in situ until after delivery. At the time of catheter removal, the length of catheter at the skin was noted, as was the elapsed time since catheter insertion. The measurements of catheter length at the skin at the time of taping and removal were compared. Inward migration was recorded as positive movement and outward migration as negative movement, to the nearest $0.5 \mathrm{~cm}$.

Following a negative test-dose of three $\mathrm{ml}, 1.5$ per cent lidocaine with $15 \mu \mathrm{g}$ of adrenaline administered through the catheter, $7-11 \mathrm{ml}$, bupivicaine 0.25 per cent was administered to establish the block and a continuous infusion of $6-9 \mathrm{ml} \cdot \mathrm{hr}^{-1}$, bupivicaine 0.25 per cent was employed to maintain the block. After establishment of the epidural block, the patient was asked if she continued to be aware of her contractions and if so, were the contractions painful? The assessment was made by the caseroom nurse caring for the patient. Analgesia for Stage I labour was graded as poor if the parturient was never free of pain after initiation of the block. Analgesia was graded as good if interventions (epidural topups with local anaesthetics or fentanyl) in addition to the infusion were required to maintain analgesia and excellent if the patient remained comfortable with the infusion alone.

Data were analyzed using the Pearson product-moment correlation coefficient to compare relationships between continuous variables and the Chi-Square test with a Yates correction, as required, to compare non-contiguous variables. Statistical significance was assumed when $P<0.05$.

\section{Results}

The catheter level at the time of removal was not measured in fourteen patients ( 0.6 per cent) which resulted in 211 completed data sheets and 14 partly completed sheets. Four patients had a second catheter inserted when no block developed with the first and the patient was assessed only after the second catheter was inserted.

The interspace utilized, the number of patients in which it was utilized and the average depth of the epidural space at each interspace is shown in Table I. The depth of the

TABLE I Details of epidural space

\begin{tabular}{lcl}
\hline Interspace & Number of patients & Average depth $\pm S D(\mathrm{~cm})$ \\
\hline $\mathrm{L}_{1-2}$ & 1 & $4.50 \pm 0$ \\
$\mathrm{~L}_{2-3}$ & 112 & $4.84 \pm 0.99$ \\
$\mathrm{~L}_{3-4}$ & 104 & $5.00 \pm 0.94$ \\
$\mathrm{~L}_{4-5}$ & 8 & $5.37 \pm 0.89$ \\
Total & 225 & $4.94 \pm 0.97$ \\
\hline
\end{tabular}

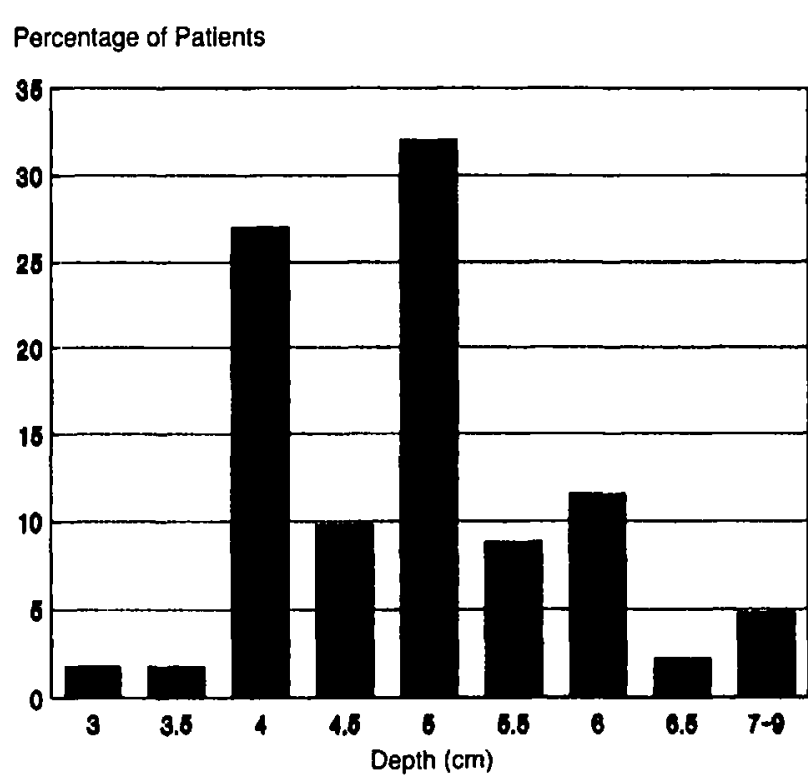

FIGURE 1 Depth of the epidural space. The depth of the epidural space from skin (cm) and the percentage of patients in whom that depth was recorded is shown.

epidural space (distance from skin) increased from $\mathrm{L}_{1-2}$ through to $\mathbf{L}_{4-5}$ (Pearson product-moment correlation coefficient 0.99); however, the differences were clinically unimportant. Seventy per cent of the epidural spaces were located $4-5 \mathrm{~cm}$ from the skin (Figure 1). Increasing depth of the epidural space was positively correlated with increasing maternal weight (coefficient 0.9 ) and increasing body mass index (coefficient 0.89 ) but not with increasing height (coefficient 0.52 ). The depth of the epidural space was greater than six $\mathrm{cm}$ in 18 per cent of parturients.

Fifty-four per cent (114/211) of the catheters migrated during labour, 46 per cent $(97 / 211)$ did not. Eighty catheters migrated outwards and 34 catheters migrated inwards. The incidence and magnitude of catheter migration (measured in $\mathrm{cm}$ to the nearest $0.5 \mathrm{~cm}$ ) are shown in Figure 2. The majority of catheters that migrated moved two $\mathrm{cm}$ or less but 26 catheters moved greater distances. The migration was not dependent on the elapsed time since insertion nor did the catheters move more often in the larger patients (BMI > 30) than in the less obese

In 38 patients the quality of analgesia was graded as poor. There was no relationship between the measured depth of the epidural space or BMI and the quality of analgesia. There was a trend towards poorer analgesia as the catheter length within the epidural space increased above four $\mathrm{cm}$ but this was not significant (Table II). There was a relationship between poor analgesia and epidural catheter migration $(P<0.05)$ (Table III) although neither the direction nor the magnitude of the 


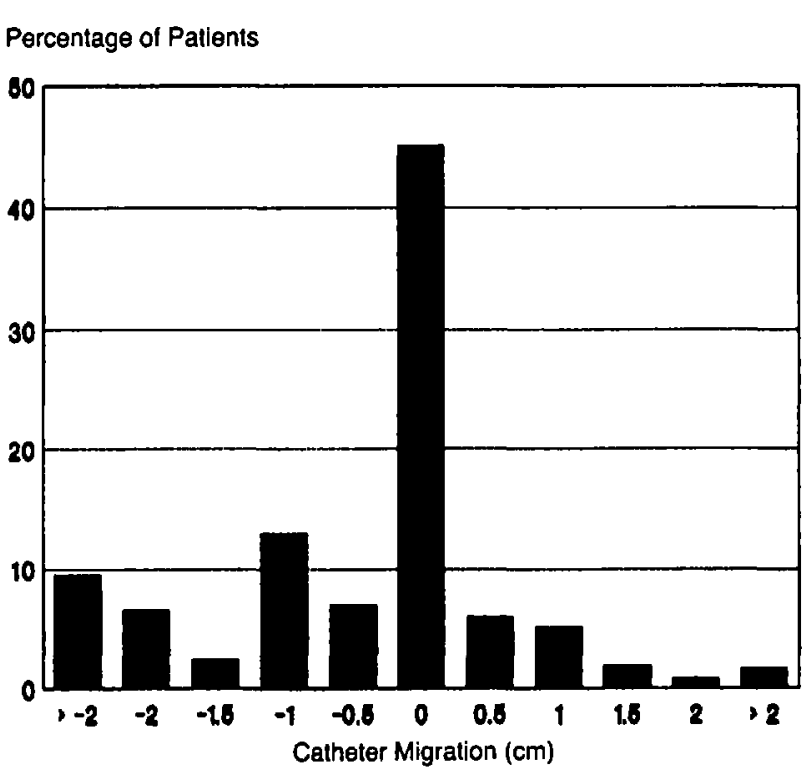

FIGURE 2 Epidural catheter migration. The percentage of catheters that migrated as well as the distance migrated is shown. Migration out of the epidural space is denoted by a negative value, zero denotes catheters that did not migrate and a positive value denotes movement into the epidural space.

migration was significantly related to poor analgesia. There was a relationship between the occurrence of poor analgesia and a duration of labour of less than two hours following insertion of the epidural catheter $(P<0.05)$. Eight of the 20 parturients ( 40 per cent) who delivered in the two hours following insertion of the epidural obtained pain relief graded as poor, compared with 30 of the remaining 205 patients (14.6 per cent). However, there was no difference between the mean durations of labour, after insertion of the epidural, in patients with poor pain

TABLE II Quality of analgesia and catheter length

\begin{tabular}{lccr}
\hline & $\begin{array}{c}\text { Catheter length } \\
\text { less than } 4 \mathrm{~cm}\end{array}$ & $\begin{array}{l}\text { Catheter length } \\
4 \text { cm or greater }\end{array}$ & Total \\
\hline Analgesia good & & & \\
$\quad$ to excellent & 46 & 127 & 153 \\
Analgesia poor & 6 & 32 & 38 \\
Total & 52 & 158 & 211 \\
\hline
\end{tabular}

TABLE III Quality of analgesia and cathether migration

\begin{tabular}{lclr}
\hline & $\begin{array}{l}\text { Migrating } \\
\text { catheter }\end{array}$ & $\begin{array}{l}\text { Stable } \\
\text { catheter }\end{array}$ & Total \\
\hline Analgesia good or excellent & 91 & 82 & 173 \\
Analgesia poor & 26 & 12 & 38 \\
Total & 117 & 94 & 211 \\
\hline
\end{tabular}

relief (305 $\mathrm{min} \pm 200 \mathrm{~min}$, mean $\pm \mathrm{SD}$ ) compared with those patients with either good (388 $\mathrm{min} \pm 218 \mathrm{~min}$ ) or excellent ( $278 \mathrm{~min} \pm 157 \mathrm{~min}$ ) analgesia.

One hundred eighty-two patients ( 82 per cent) delivered spontaneously and 24 patients $(10.6$ per cent) were delivered with either low forceps or vacuum extraction. Nineteen patients ( 8.4 per cent) were delivered by Caesarean section, 13 because of cephalopelvic disproportion or failure to progress in labour, five because of fetal distress and one each for abruptio placenta and previously undiagnosed breech presentation.

\section{Discussion}

Epidural block is felt by many to represent the ideal mode of labour analgesia. However, inadequate analgesia is not uncommon and unilateral or patchy blocks occur in 5-20 per cent of all blocks. ${ }^{3}$ In this study, the overall incidence of unsatisfactory analgesia was 17 per cent. The most common cause cited for poor block is incorrect catheter placement. The catheter may be threaded in the extraspinal space between the deep interspinous ligament and the ligamentum flavum, resulting in no or poor block.

Narang has suggested that deviation of the needle from the midline may result in the needle entering the lateral epidural space. ${ }^{4}$ The catheter may then be inserted in the lateral or anterolateral epidural space and a unilateral block may result. Within the anterior epidural space, trabeculations are common between the ventral dura and the posterior longitudinal ligament, rendering the space discontinuous across the midline, anteriorly. With the catheter tip in the anterior space, contralateral block becomes dependent on retrograde flow of the anaesthetic solution around the circumference of the dural space. ${ }^{5,6}$ Narang estimated that, if the epidural space was identified at greater than $6 \mathrm{~cm}$ depth from skin (eight per cent of his patients), then there was a greater than 40 per cent chance of an unsatisfactory block. His hypothesis was that, the greater the depth at which the epidural space is entered, the higher the likelihood that the lateral aspects of the space have been entered. However, Harrison, in reviewing 1000 parturients, noted that the epidural space was 6 $\mathrm{cm}$ or greater from the skin in 20 per cent of patients. ${ }^{7}$ In our series, 18 per cent of the parturients had skin to epidural space distances of $6 \mathrm{~cm}$ or greater and increasing depth of epidural space was not associated with poor analgesia. Palmer has previously reported, and our study confirms that increasing depth of the epidural space in the obstetrical population correlates with increasing body mass index.$^{8}$ (Our patient population may have differed from that of Narang in this regard.)

Usubiaga and others have suggested that limiting the length of catheter inserted into the epidural space may reduce the incidence of inadequate blocks. ${ }^{3,5,9}$ Inserting 
greater lengths may allow the catheter to move into the anterolateral epidural space, once again resulting in a unilateral block. Contralateral block may be favoured by increased volumes of anaesthetic solution, positioning the patient with the unblocked side down, or by withdrawing the catheter. It has been demonstrated, radiographically, that seven per cent of epidural catheters inserted $12.5 \mathrm{~cm}$ or greater into the epidural space leave the space through intervertebral foramena and that 40 per cent of catheters inserted in a cephalad direction do not pass the first interspace before changing course. ${ }^{9}$ Hood has recommended limiting epidural catheter insertion to less than 4 $\mathrm{cm}$ so as to decrease the incidence of poor block. ${ }^{3}$ We analysed our data to see if we could demonstrate an association between increasing length of catheter in the epidural space (greater than $4 \mathrm{~cm}$ ) and unsatisfactory block. Although there was a trend towards poor analgesia in our patients who had greater than $4 \mathrm{~cm}$ of catheter within the epidural space, it was not significant. (However, we agree with the clinical guideline advanced by Hood.)

Catheters were replaced in 1.7 per cent of patients in this study. This is lower than the five per cent reported by Hood and perhaps more aggressive replacement of poorly functioning catheters would have decreased the incidence of inadequate analgesia. ${ }^{3}$

Patients who delivered within two hours of the insertion of the epidural were more likely to obtain poor analgesia than those patients who delivered more than two hours later. This may be related to the difficulty sometimes encountered in providing good analgesia to patients with rapidly progressing labours, although we were surprised that this effect could persist for up to two hours.

The role of epidural catheter migration in inadequate or failed epidural blockade has received little attention. The multi-holed catheters that we employed have the first hole $0.8-0.9 \mathrm{~cm}$ from the catheter tip and the third hole $1.7-1.9 \mathrm{~cm}$ from the tip. If the catheter is inserted $3-4 \mathrm{~cm}$ into the epidural space, the last hole may be as little as 1.1 $\mathrm{cm}$ into the space. Outward migration of the catheter, even over short distances, may then result in displacement of one or more orifices outside the epidural space, with obvious implications of the resulting block. Philips assessed 100 obstetrical epidurals and noted migration in 54 per cent. ${ }^{10}$ In his series, twice as many catheters migrated into the space as out of it, raising concerns about blood vessel puncture or subarachnoid migration with subsequent misplaced injection or eventual development of unilateral analgesia. A similar percentage of catheters migrated in our series as in Phillips', although the direction of migration was reversed. Twice as many of our catheters migrated out of the space as compared with those migrating inward. Although, in both series, the majority of the migrations were $2 \mathrm{~cm}$ or less, a similar percentage of catheters was displaced greater distances, 16 per cent in Phillips series, 23 per cent in ours. Even 2 $\mathrm{cm}$ of outward migration has implications for the multiholed catheter inserted $3 \mathrm{~cm}$ into the epidural space. A greater number of topups, higher infusion rates or eventual failure of the catheter might be anticipated. Philips noted no correlation between catheter migration and the quality of analgesia, whereas in our series there was a significant relationship between catheter migration and poor analgesia. This difference may be explained by the predominant outward direction of the migration in our series. Cherala has recently reported an association between catheter migration into the epidural space and the occurrence of unilateral obstetrical analgesia. "The catheters were pulled back to their previous position and effective bilateral analgesia was restored in all patients.

The optimum distance for insertion of epidural catheters is probably $3-4 \mathrm{~cm}$. Unfortunately, with a multiholed catheter, migration outwards may result in unsatisfactory analgesia. The use of an end-holed catheter may reduce the likelihood of a poor block secondary to small amounts of catheter migration. New methods of securing the catheter to the skin have been described but their effect on catheter migration has yet to be assessed. ${ }^{12}$ Finally, recording the depth of the epidural space and the depth of the catheter at the skin and using this information to assess catheters that initially produced an effective block, but over time provided inadequate analgesia, may allow simple but effective trouble-shooting of these problem catheters.

\section{Acknowledgements}

The cooperation of the anaesthesia residents providing the obstetrical epidural service, as well as Mme. Helen Dudas and the caseroom staff at the Ottawa General Hospital, made this study possible.

\section{References}

I Bromage PR. Epidural Analgesia. 2nd ed. London: Saunder 1978.

2 Doughty A. A precise method of cannulating the lumbar epidural space. Anaesthesia 1974; 29: 63-5.

3 Hood DD. Obstetric anesthesia: complication and problems. In: Problems in Anesthesia, Kirby RR, Brown DL (Eds.). Obstetric Anesthesia, Hood DD (Guest Ed.) 1989; 3: 1-18.

4 Narang VPS, Linter SPK. Failure of extradural blockade in obstetrics: a new hypothesis. Br J Anaesth 1988; 60: 402-4. 
5 Usubiaga JE, Dos Reis A, Usubiaga LE. Epidural misplacement of catheters and mechanisms of unilateral blockade. Anesthesiology 1970; 32: 158-61.

6 Boezaart AP. Computerized axial tomo-epidurographic and radiographic documentation of unilateral epidural analgesia. Can J Anaesth 1989; 36: 697-700.

7 Harrison GR, Clowes NWB. The depth of the epidural space from the skin. Anaesthesia 1985; 40: 685-7.

8 Palmer SK, Abram SE, Maitra AM, von Colditz JH. Distance from the skin to the lumbar epidural space in an obstetric population. Anesth Analg 1983; 62: 944-6.

9 Sanchez $R$, Acuna $L$, Rocha $F$. An analysis of the radiological visualization of the catheters placed in the epidural space. Br J Anaesth 1967; 39: 485-9.

10 Philips DC, MacDonald R. Epidural catheter migration during labour. Anacsthesia 1987; 42: 661-3.

11 Cherala SR, Sheth $R$, Mehta D, Greene RI. Fixing the epidural catheter in place - the way we see it. Regional Anesthesia 1989; 14: 158.

12 Pither $C$, Hartrick C. Postoperative pain. In: Raj PP (Ed.). Handbook of Regional Anesthesia. New York: Churchill Livingstone 1985: 99-108. 